\title{
On Development and Change of Cucurbit Flute Music of the Dai Ethnic Group in Yunnan
}

\author{
Zilong Song \\ Qujing Normal University, Qujing Yunnan, 655011, China
}

\begin{abstract}
Keywords: Cucurbit Flute, The Dai Ethnic Group in Yunnan, Change, Playing Technique, Musical Works, Inheritance
\end{abstract}

\begin{abstract}
In the language of the Dai ethnic group in Yunnan, "Bi Langdao" refers to cucurbit flute, which is a wind instrument made out of a cucurbit. Cucurbit flute emerged as early as in the Pre-Qin period, so it represents the culture foundation of the Dai ethnic group. With the development of times, the playing technique, the form of expression and the social inheritance of cucurbit flute music all have greatly changed. In this article, it is planned to expound these aspects, with a view to exploring the emergence, development and evolution of cucurbit flute music of the Dai ethnic group in Yunnan.
\end{abstract}

\section{Introduction}

Cucurbit flute can be dated back to a thousand years ago. Presently, its natural and traditional form has been widely accepted by popular and professional musicians. Through constant evolution and improvement, it has become a "five-good (melodious, good looking, easy to learn, portable, widely available) " instrument popular in the ethnic music of the Dai. In recent years, with the popularization of musical culture via multimedia, more and more people get to know and recognize cucurbit flute music, which also affects cucurbit flute music in every aspect in return, and contributes to the innovation and improvement of cucurbit flute music to get a sound development.

\section{Development and Evolution of Playing Technique of Cucurbit Flute}

Cucurbit flute is a traditional folk wind instrument, of which the sound is melodious and touching. With the constant innovation of musical culture and techniques, cucurbit flute also should advance with the times, and be improved based on the practice of musical creation and the research of musical instrument over the years.

\section{Innovation and Evolution of Traditional Playing Techniques}

\section{Range Expansion}

The tone setting and key setting of traditional cucurbit flute are fixed, so that narrow range is a prominent defect in the performance, and it is not possible to overblowing the cucurbit flute like playing the bamboo flute. For example, the lowest pitch of cucurbit flute is 5 when all the seven sound holes are closed, and the highest pitch is 6 when all the seven sound holes are open. This implies that the range of cucurbit flute is relatively narrower other similar instruments, which has hampered the development of cucurbit flute music. In the late of the 1950s, some breakthroughs had been made in the range of cucurbit flute, whose pitches had been expanded from 8 to 14 . So far, there even are some cucurbit flute enthusiasts have made cucurbit flute of new type, such as six-tube cucurbit flute. With a six-tube cucurbit flute, single note, dual tone can be played, single counterpoint sustained tone and dual counterpoint sustained tone can be played. Such an innovation has greatly improved the volume, range and timbre of cucurbit flute.

In this article, a new type 8-hole cucurbit flute which is specially developed for purpose of range expansion will be introduced. This new type has improved the defect of narrow range of traditional cucurbit flute (has 11 pitches including 3 low pitches and 6 high pitches, with which it is impossible to play high pitch). In comparison, the hole number of the 8-hole cucurbit flute is more that that of the traditional 7-hole cucurbit flute, and the close-pipe pitch has been moved down by 2 pitches. Take the example of the close-pipe pitch, namely low pitch 5. In case of starting with low pitch 5, the players 
will certainly open the sixth hole first (pressed by a finger of the right hand), and then upwards, and the position of the first thumb of the left hand on the back of the main tube is exactly the position of high pitch 1. If the holes 6 and 7 are pressed concurrently, and other holes are open, then a sound will be made as the 7-hole cucurbit flute does. If an 8-hole cucurbit flute is adopted, high pitches 1 and 7 can be played. In this way, cucurbit flute can be applied to play more musical compositions. Innovation in Modulation

Replacement of cucurbit flute is required for a traditional cucurbit flute to realize modulation. However, with the expansion of range, modulation becomes realizable by only one cucurbit flute.

Comparing with the narrow-range cucurbit flute, the mode pattern position of a broad-range cucurbit flute has been moved, which also has changed the traditional fingering. Generally, a traditional cucurbit flute can play at least 6 pitches. However, limited by the arrangement of scale and range, a traditional cucurbit flute actually can modulate four pitches, and only low pitch 5 (close-pipe pitch) and pitch 1 are the frequently-used pitches of a traditional cucurbit flute. Take the example of a cucurbit flute of C. Besides C, D with a close-pipe pitch 4 and F with a close-pipe pitch 2 also can be played with such a cucurbit flute. Theoretically, it has realized the six tones called in folk music, but there are still some limitations in playing the music with it.

\section{New Playing Technique in Modern Times}

\section{Respiratory Method}

Besides the innovation in the traditional playing techniques, many new independent playing techniques have developed. For example, the common circular breathing adopted to playing the traditional cucurbit flute is chest breathing, but the position of breathing for playing the modern cucurbit flute has been moved down to the abdomen or the chest-abdomen. The latter two respiration methods emerge to address the need of playing new cucurbit flute music works. The traditional chest breathing method is demanding for the player in respiration, including the respiration frequency and the respiration quality. The chest-abdomen breathing emphasizes mobilizing the muscles, to completely present the respiration rhythm according to the performance intention, and form coherent circular respiratory airflow. This facilitate the breathing of the players to perform a long song coherently.

The players must have much exercises to realize the coherence of respiration and breathing of mouth, nose, chest and abdomen, which is demanding for the players in coordinating the breathing with the playing. The coordination between the breathing and the playing requires that the mouth, lung and abdomen organically coordinate with each other, and good respiration exchange. Thus, the circular chest-abdomen breathing is believed to be the best respiration method for playing the cucurbit flute at present. With this method, more full, coherent and forceful sound can be made.

Fingering Change between Half-step and "Coo" Tone

Half-step is the most useful skill in playing the cucurbit flute, and there are many fingering methods developed for playing half-step. As the cucurbit flute musical works become more and more complicated, temporary half-step becomes common in many works, which should be played with "Coo" tone with varying fingering methods. The advantage of playing temporary half-step with "Coo" tone is to simplify the fingering methods. Hence, the importance of "Coo" tone in playing half-step should not be ignored.

There are rich fingering skills to play "Coo" tone, such as the unique single slide and compound slide. The player need to press all holes, and gently play low pitch 3 . If the first hole is opened, low pitch \#4 will be made. Low pitch 5 and the like can be made in this way. If holes 1 to 3 are opened consecutively, a upward slide of low pitch 5 will be made. Conversely, if holes 3 to 1 are closed consecutively, a downward slide of low pitch 3 will be made. If the player repeatedly closes or opens the three holes in such a way, a compound slide from low pitch 3 to low pitch 5 can be made. This kind of fingering method is common in playing the Shepherd's Melody, the Butterfly Lovers, etc. Comparing with the performance way in which no single slide and compound slide was adopted in the past, the two melodies mentioned above are presented more excellent in voice and affection by 
applying "Coo" tone, and slide also makes the transition of affection in the melodies more natural and smooth[1].

\section{Development and Evolution of Expression Form and Musical Works of Cucurbit Flute}

\section{Development and Evolution of Expression Form}

The development and evolution of playing skills have contributed to the innovation of cucurbit flute music in expression form. In order to show the ethnical features and art expressive force of cucurbit flute music, more novel modern musical elements have been integrated into cucurbit flute music based on the traditional musical styles of the Dai, which have greatly beautified cucurbit flute music.

\section{Multiple Playing Forms}

Traditional cucurbit flute is used to play solo or together with other folk instruments. Nowadays, many performance forms have been derived from solo, including new solo, concert, ensemble, and unison, having enriched the expression form of cucurbit flute, and making cucurbit flute "not solo anymore". Considering the diversified demands and the emphasis laid on coordination of multiple instruments in modern music, the solo of cucurbit flute music is preserved just for preserving the tradition, such as small-scale performance of 2-5 players. The players play each part of a melody with cucurbit flutes with different ranges respectively, to present a melodious and rhythmic chorus, which involves high-pitched, mediate-pitched and low-pitched cucurbit flutes. Besides, concert of cucurbit flute of hundreds of players also becomes common in folk concert nowadays. For example, the melody of the Top Music (天乐) is a large work played by 300 players with different cucurbit flutes. Go with Electronic Music

The combination of traditional cucurbit flute with electroacoustic music which was beyond imagination in the past becomes popular and common today. For example, the Cucurbit Flute (月光 下的凤尾竹) is a work played in such a way. On one hand, this playing mode has reserved all range characteristics of cucurbit flute. On the other hand, the range of cucurbit flute has been greatly expanded via electroacoustic music, and the high pitch also becomes fuller, which corresponds more with the pursuit of aesthetic feeling of music of contemporary people.

In a word, the spirit of self breakthrough and the courage to practice of cucurbit flute enthusiasts are indispensible to the development of playing form of cucurbit flute from solo to concert.

\section{Evolution of Form of Musical Works}

As development and evolution over the past years, the cucurbit flute music works also have greatly changed. Take the example of the Cucurbit Flute (月光下的凤尾竹) and the Epic Song (古歌), which are the typical works in the playing of cucurbit flute. The scale, mode and rhythm of the two works all have greatly changed.

Scale and Mode

Since a traditional cucurbit flute just has a five-tone scale, the expression of the two melodies with a traditional cucurbit is relatively dull. Especially, many half-steps cannot be expressed clearly and sharply. The improved cucurbit flute has reached the conditions of seven-tone scale, and can be used as a transposing instrument, with which both the seven-tone mode in traditional Chinese folk music and various western modes can be played.

Rhythm

The playing skills of cucurbit flute have been greatly improved. Take the example of the Cucurbit Flute (月光下的凤尾竹). The newcomers constantly add new music elements to perform this melody, having made great innovations. For example, the inherent beats in this melody are 2/4, 3/4, 4/4 and $6 / 8$, and only one among these beats could be employed at one time in the past. Nowadays, it has been realized to perform multiple parts of this melody with multiple beats by means of concert, without impact on its features of ease, softness and grace and its rhythm. 
Since we entered the new century, modern cucurbit flute musical works have been prospering, of which the quantity reaches 9 times of that of the traditional works. This has reflects the degree that people emphasize the research of cucurbit flute music. Thanks to the constant innovation and diversification of the theme, cucurbit flute music is advancing with the pace of popular music in reliance upon long-term and continuous innovations[2].

\section{Development and Evolution of Inheritance of Cucurbit Flute}

Actually, the inheritance of cucurbit flute music is not special, including two modes according to its expression mode and folk art characteristics, namely automatic inheritance and inheritance via non-government organizations.

\section{Automatic Inheritance}

In Lianghe county (Yunnan), cucurbit flute has been being inherited well via automatic inheritance plus family inheritance. Regarding the history of development of cucurbit flute in Lianghe, the inheritance of fabrication, playing techniques, and musical craft was carried out mainly by the unit of household, and has been gradually evolved to a mode dominated by automatic inheritance and supplemented by family inheritance.

In Lianghe County, cucurbit flute is regarded a media of love and marriage between young boys and girls, which is another reason why it can be well inherited. Such a social function, together with the local manners and customs of the Dai, has greatly contributed to its inheritance. The ancient melody and ancient love songs of the Dai appear more special. "Ancient love songs" are called "Xing Bi Ban Tao (in dialect)" in the Dai, which are performed with cucurbit flute only; the performance of "Han Ban Tao (in dialect)" can include playing the cucurbit flute and singing concurrently. Both the two patterns, which stand for the eternal and pure love and is a form of externalizing the affection and ideas of the Dai people via the cucurbit flute, have been inherited by the Dai people generation by generation.

\section{Inheritance via Non-government Organization}

The pattern of inheritance via non-government organization of cucurbit flute music is further divided into to sub-patterns, namely inheritance via school education and inheritance via social organization.

Inheritance via School Education

The history of the cucurbit flute in Lianghe can be dated back to a thousand years ago, so it has a wide mass base. Nowadays, people still remain enthusiastic about the inheritance of cucurbit flute music culture. Since the late 1990s, various educational institutions and training institutions specialized in cucurbit flute have been mushrooming, and national cucurbit flute music contests also have been prospering. Importance is attached to the training of young cucurbit flute talents and the exchange of musical craft among cucurbit flute learners, which has greatly promoted the development of cucurbit flute music, and the popularization of cucurbit flute to the entire China and even the entire world.

\section{Inheritance via Social Organization}

Since 2011, a cucurbit flute association consisting of cucurbit flute enthusiasts has been established in Lianghe County, and its scale has been constantly expanded with the expansion of the market size of cucurbit flute. Although the history of the association is not long, it is considerably competent now, and has basically realized the popularization of cucurbit flute music in Lianghe area. That at least 30 sessions of cucurbit flute music and culture training and exchange will be held a year has greatly promoted the development of the cucurbit flute industry in local area and even the whole area of the Dai ethnic group in Yunnan, making the industrialization of cucurbit flute culture get on the right track of social development[3]. 


\section{Conclusion}

Throughout the long history of China, most art forms with ethnic characteristics and features have gradually declined and fallen. In spite of this, the cucurbit flute of the Dai ethnic group in Yunnan shows its vitality, which has something to do with its systematic and diversified inheritance mode, and also decided its development environment. More importantly, the Dai people love cucurbit flute music art so much that they hand down cucurbit flute as a part of their life generation by generation.

\section{Acknowledgement}

A phased achievement of the topic of the Innovation Team of Contemporary Music and Art in Yunnan launched by Qujing Normal University .

\section{References}

[1] SONG Lu. Brief on the Origin and Features of Cucurbit Flute Culture and Art in Dehong in Yunnan. Culture and Art · Art and Literary Circle, 2013, (4): 140-141.

[2] YE Hong, DONG Ruofei. Brief Analysis of Evolution of Social Function of Cucurbit Flute-Lianghe County in Dehong Prefecture. Theory Research, 2014, (1): 165-166.

[3] MENG Meng. Research on Traditional Cucurbit Flute of the Dai Ethnic Group and the Music Evolution thereof-Development and Evolution of Cucurbit Flute of the Dai Ethnic Group in Lianghe County in Dehong Prefecture. Minzu University of China, 2013. 37-58. 